Old Dominion University

ODU Digital Commons

VMASC Publications

Virginia Modeling, Analysis \& Simulation Center

2010

\title{
Route Change Decision Making by Hurricane Evacuees Facing Congestion
}

R. Michael Robinson

Old Dominion University, rmrobins@odu.edu

Asad Khattak

Old Dominion University

Follow this and additional works at: https://digitalcommons.odu.edu/vmasc_pubs

Part of the Civil Engineering Commons, Emergency and Disaster Management Commons, Transportation Commons, and the Transportation Engineering Commons

\section{Repository Citation}

Robinson, R. Michael and Khattak, Asad, "Route Change Decision Making by Hurricane Evacuees Facing Congestion" (2010). VMASC Publications. 27.

https://digitalcommons.odu.edu/vmasc_pubs/27

\section{Original Publication Citation}

Robinson, R. M., \& Khattak, A. (2010). Route change decision making by hurricane evacuees facing congestion. Transportation Research Record, 2196, 168-175. doi:10.3141/2196-18

This Article is brought to you for free and open access by the Virginia Modeling, Analysis \& Simulation Center at ODU Digital Commons. It has been accepted for inclusion in VMASC Publications by an authorized administrator of ODU Digital Commons. For more information, please contact digitalcommons@odu.edu. 


\title{
Route Change Decision Making by Hurricane Evacuees Facing Congestion
}

\author{
R. Michael Robinson and Asad Khattak
}

Successful evacuations of metropolitan areas require overcoming unexpected congestion that reduces traffic flows. Congestion may result from accidents, incidents, or other events that reduce road capacity. Traffic professionals and emergency managers may promote deviations from planned routes to bypass an area of congestion and speed mass exit. However, some route changes may actually reduce traffic flow rates, and in these cases decision makers may want to discourage use of alternate routes. By using results of a behavioral survey of potential hurricane evacuees, this study identifies variables associated with the decision to alter routes and also identifies frequently used information sources. A dynamic traffic simulation with a decision-making model using this information is proposed as a means for evacuation decision makers to assess impacts of driver decisions. Results from more than 800 responses showed the potentially strong influence of effective advanced traveler information systems to support decisions made by hurricane evacuees on whether to use an alternate route when faced with congestion. Results of this study are a timely contribution to those seeking a better understanding of driver behavior during evacuations and improvement of emergency management efficiency and efficacy.

The success of a hurricane evacuation may be measured by the safe and timely movement of affected citizens to safety. Evacuation managers may accept extended travel times for some evacuees to reduce the total time for all evacuees to reach safety. The difficulty of conducting a successful evacuation is increased by realtime events beyond a planner's ability to control. Road capacities may be reduced by accidents and incidents, adverse weather, infrastructure failures, or disorderly behavior. Wise use of intelligent transportation systems, in particular the advanced traveler information system (ATIS), and active traffic management may allow planners and engineers to influence driver decisions to use available alternate routes and improve overall traffic flow. This research assesses the influence of various factors on drivers' decisions on whether or not to divert to an alternate route when faced with congestion during an evacuation. Understanding these influences may allow more effective use of ATIS and improve transportation management during crisis situations. The objective of this paper is to understand route change decision making by hurricane evacuees facing traffic congestion.

R. M. Robinson, Virginia Modeling, Analysis, and Simulation Center, and A. Khattak, Civil and Environmental Engineering Department, 135 Kaufmann Hall, Old Dominion University, Norfolk, VA 23529. Corresponding author: R. M. Robinson, RMRobins@odu.edu.

Transportation Research Record: Journal of the Transportation Research Board, No. 2196, Transportation Research Board of the National Academies, Washington, D.C., 2010, pp. 168-175

DOI: $10.3141 / 2196-18$

\section{LITERATURE REVIEW}

A review of past evacuations and evacuation studies reveals several simulations that focus on different types of evacuations or aspects of the evacuation process. Baker's study of evacuation behavior included the identification of several reasons why individuals affected by a hurricane chose not to evacuate (1). These included the desire to protect property from the storm and looters, work requirements, peer pressure, difficulty of preparing, and concerns over traffic, pets, and destination choice. Baker also noted that advice or orders from public officials may affect evacuation rates more than any other factor. Researchers hypothesized that these factors may also influence decisions made during an evacuation.

Prater et al. examined the distribution of information during Hurricane Bret and noted distinct differences in the way that residents used various information sources in the evacuation decision (2). The study included a lengthy survey and gathered significant information on affected residents, the information desired and received, and actual decisions made. It found that television networks were the most important source of information, followed by local radio broadcasts. Local newspapers and the Internet were the least important information sources. Significant advances in the use of the Internet, via fixed computers and mobile devices, was expected to change this ranking. Lindell et al. examined the process used by coastal Texas residents deciding whether or not to evacuate in response to Hurricane Lili (3).

Southworth (4), Southworth and Chin (5), Hobeika and Kim (6), and Fu et al. (7) provide excellent information on modeling the rate at which evacuees enact an evacuation decision. The latter paper provides especially valuable insight for those wishing to model the impact of different variables and conditions on evacuee response rates and provides an example of assessing the importance of different variables. Wilmot and Mei compared the relative accuracy of various forms of trip generation for evacuating traffic, testing different models by using data from an actual evacuation (8). Barrett et al. provide sound guidance on the development of dynamic traffic models for hurricane evacuations, including considerations that must be accounted for in an accurate representation (9). MurrayTuite and Mahmassani used trip chain simulations to accurately predict delays and traffic densities occurring before an evacuation begins in earnest (10). Two comprehensive papers by Wolshon et al. discuss areas that should be considered in the creation of a successful evacuation plan $(11,12)$. Robinson et al. assessed the impact of accidents and incidents on the time to complete an evacuation of affected residents of a large metropolitan area (13). Liu et al. proposed a cellbased network model to determine optimal staging schemes (14). The model used demand generation to reduce congestion on an evacuation network by providing a more uniform distribution of demand and showed the critical importance of assigning proper times for 
beginning the evacuation from each of the staged zones. Dixit and Radwan looked at the congestion that occurs during evacuations as a result of a large number of evacuating vehicles overloading the limited capacity of exit ramps offloading traffic onto the heavily loaded network of a destination city (15). They used microscopic modeling and a process they call "network breathing" to propose a system of external controls of evacuating vehicles' entry and exit into the evacuation network, to manage congestion and thus improve outflow.

Mehndiratta et al. used information from the ongoing Puget Sound Regional Council's transportation panel travel diary study to identify likely ATIS user groups and showed the potential of segmenting users by travel purpose, demographics, and technological savvy as well as other factors (16). Goulias et al., by using a later year's version of the same Puget Sound study, examined the relationships between technology ownership and availability, ATIS awareness, and frequency of ATIS use (17). Their focus on awareness and use of available information probed an area still not well documented: Although many types and sources of information have become available, who are the users and how is the information used? Khattak et al. studied the impact of ATIS use on route decisions during the pretrip stage, including the impact of congestion source information, trip characteristics, and route attributes (18). Khattak et al. furthered work in this area by examining whether the increase in the number of publicly available travel information sources is associated with a higher likelihood of travel decision changes and also which ATIS technologies are used most frequently or with the greatest influence (19). A more recent study on the impact of ATIS shows that travel characteristics, the time of information provision (pretrip versus en route), the source, and the content of information significantly affect commuters' switching decision (20).

These papers and others provide significant information useful to those who must plan and manage large-scale evacuations. However, little effort has gone into assessing the decisions made by drivers who feel an urgent need to reach their destinations (such as during a hurricane evacuation) when faced with congestion. This study explores the variables associated with decision making and then models the impact of the decisions in a dynamic evacuation simulation.

\section{METHODOLOGY}

Beginning with the knowledge on information types and sources from the literature review, a behavioral survey was used to gather information on driver characteristics and preferences. A pilot survey was distributed to assess the adequacy of the questions and identify areas requiring modification. The survey was refined and a final survey was made available in hard copy and electronic form by using a commercial Internet survey product.

In addition to demographic data (gender, age, income, education, etc.), the survey identified information types and sources of most concern to potential hurricane evacuees, allowing development of a decision-making model and assessment of the impact of decisions that might be made on evacuation traffic flow. It also gathered information on how participants responded when previously faced with congestion and the extent of their preparedness for a future evacuation and obtained a self-assessment on how they might respond to congestion during a future evacuation when provided with different levels and types of traffic information. Survey participants learned of the study and participated as a matter of convenience; respondents do not represent a random sampling of the regional population. Survey participants were found by word of mouth, via announcements posted on the research center and university websites, and via an e-mailed request for participants from the regional metropolitan planning organization. Approximately 900 survey responses were received. After excluding responses that failed to answer a substantial number of key questions, 841 valid surveys were considered. Of these, $631(75 \%)$ were randomly selected for analysis and the remaining $210(25 \%)$ reserved for validation testing.

Characteristics of the sample population are provided in Tables 1 and 2 (listed alongside regional demographics in Table 1). The regional values were obtained from the Virginian-Pilot summary of The Scarborough Report 2006 (21). The respondent population was older and better educated and had higher annual earnings than were found in the general population.

One way to partially overcome whether the sample is representative is to use weights in statistical analysis. Therefore, to explore the implications of differences in socioeconomics between the survey and the regional population, respondents were segmented into demographic groups and responses were statistically weighted by age and gender. This was intended to more accurately reflect each groups' fraction of the total regional population. The results showed that demographic factors appeared to have little impact on the decisions made (e.g., divert or not in response to unexpected congestion). The single largest difference between weighted and nonweighted cate-

TABLE 1 Survey Respondents and Hampton Roads Regional Demographics

\begin{tabular}{|c|c|c|c|}
\hline & \multicolumn{2}{|c|}{$\begin{array}{l}\text { Survey } \\
\text { Demographics }\end{array}$} & \multirow{2}{*}{$\begin{array}{l}\text { Region } \\
(\%)\end{array}$} \\
\hline & Number & $\%$ & \\
\hline \multicolumn{4}{|l|}{ Gender } \\
\hline Male & 392 & 48.4 & 49 \\
\hline Female & 394 & 51.6 & 51 \\
\hline \multicolumn{4}{|l|}{ Age } \\
\hline $18-24$ & 20 & 2.4 & 15 \\
\hline $25-35$ & 96 & 11.4 & 18 \\
\hline $36-45$ & 162 & 19.3 & 20 \\
\hline $46-55$ & 251 & 29.8 & 19 \\
\hline $56-65$ & 197 & 23.4 & 13 \\
\hline$>65$ & 84 & 10.0 & 15 \\
\hline Not reported & 31 & 3.7 & \\
\hline \multicolumn{4}{|l|}{ Education } \\
\hline $\begin{array}{l}\text { Up to high school } \\
\text { graduate }\end{array}$ & 43 & 5.1 & 34 \\
\hline Some college & 159 & 18.9 & 29 \\
\hline College degree & 305 & 36.3 & 14 \\
\hline Advanced degree & 302 & 35.9 & 11 \\
\hline Not reported & 32 & 3.8 & \\
\hline \multicolumn{4}{|c|}{ Annual Household Income } \\
\hline$<\$ 20,000$ & 20 & 1.1 & 6 \\
\hline$\$ 20,000-\$ 50,000$ & 115 & 13.7 & 37 \\
\hline$\$ 50,000-\$ 75,000$ & 156 & 18.5 & 23 \\
\hline$>\$ 75,000$ & 488 & 58.0 & 35 \\
\hline Not reported & 73 & 8.7 & \\
\hline
\end{tabular}


TABLE 2 Additional Respondent Information

\begin{tabular}{ll}
\hline Characteristic & Percent \\
\hline Would require special lodging & 20.2 \\
Would travel with others (not alone) & 84.4 \\
Would travel with children (under 18) & 46.4 \\
Have planned for an evacuation & 57.4 \\
Traffic information sources used while driving & Radio: 91.2 \\
& ATIS: 72.0 \\
& Phone: 48.5 \\
& Internet: 36.4 \\
Confident in ATIS information & GPS: 32.8 \\
Two or more vehicles in household & 64.6 \\
\hline
\end{tabular}

NOTE: ATIS = advanced traveler information system. GPS = global positioning system.

gory choices for the divert decision was just $1.3 \%$, with most differences less than $0.5 \%$. This result was contrary to expectations at the study's outset that the information type and source and the importance of the information gained to the decision choice could be correlated with demographic factors and the information's influence on the decision. The consistency of compared weighted and nonweighted responses supports use of survey results as an approximation of the region's residents. However, Mehndiratta et al. note that users of ATIS tend to be wealthier and better educated than the general population and this group is overrepresented in this study's respondents (16). A follow-on survey controlled to ensure that a regionally representative random sample would be beneficial.

By using stated preference questions, four primary scenarios were tested, each addressing the same progression of increasing congestion, but with different information levels being provided. Each scenario included only a single detour decision. Each respondent was asked the likelihood of diverting or remaining on the current route for each situation and information scenario. These categories are provided in Table 3. Responses for each scenario were assigned variable names in the format DlyTraf__. The first variable, DlyTrafSlow, is labeled to indicate traffic had just begun to slow. Numbers follow- ing the $\mathrm{X}$ in a variable name indicate the length of the congested period in minutes and the type of information provided.

\section{ANALYSIS}

The goal of the study was to identify the key factors associated with evacuees' decisions on whether or not to exit their planned path and take an alternate route when faced with significant traffic congestion during an evacuation approximately $2 \mathrm{~h}$ into the evacuation. Approximately 50 specific questions were asked and response frequencies for more than 100 individual variables recorded. Of the survey respondents, $11 \%$ indicated that they would most likely evacuate in advance of a Category 1 hurricane and slightly less than $40 \%$ reported that they would expect to evacuate for a Category 2 hurricane. In addition, $25 \%$ said they had previously evacuated for a hurricane (while they were of adult age), with $40 \%$ having done so within the past 5 years. Approximately $40 \%$ of respondents reported that their planned destination was some form of commercial lodging, 54\% planned to go to the home of a friend or relative, and the rest intended to use public shelters or other accommodation. All respondents were asked to assume that they had already made the decision to evacuate before answering questions related to a detour decision.

Previous work by Robinson included dynamic simulations of hurricane evacuations from the region (22). By using the developed simulation and assuming a realistic participation rate and the greater than normal congestion expected in an evacuation, it was found that the time required for Category 2 storm evacuees to clear the region ranged from 2 to $5 \mathrm{~h}$ and the time to reach planned destinations typically ranged from 2 to $7 \mathrm{~h}$. Under nonevacuation conditions, the same trips would require 2 to $4 \mathrm{~h}$. Although evacuees can face traffic congestion at any time during their trips, in the survey, participants were told only that the congestion was encountered $2 \mathrm{~h}$ after starting to evacuate without adjustment for the expected duration of the individual respondent's evacuation. A time $2 \mathrm{~h}$ into an evacuation was chosen because this is the approximate time required to travel from the center of the region to its outskirts under very heavy traffic conditions, such as those seen on weekends or holidays.

Table 4 shows the percentage of respondents indicating that they would take an alternate route after congestion of the shown duration

\section{TABLE 3 Traffic Situations and Information Scenarios}

\begin{tabular}{|c|c|}
\hline Situation & Information Scenario ${ }^{a}$ \\
\hline $\begin{array}{l}\text { Assume traffic has slowed to less than } 10 \mathrm{mph} \text { and the next } \\
\text { exit is visible, but you have seen no information signs. }\end{array}$ & No situational information provided. (DlyTrafSlow) \\
\hline $\begin{array}{l}\text { Traffic has continued to move very slowly for over } \\
30 \text { minutes. }\end{array}$ & $\begin{array}{l}\text { The next exit is visible. ATIS says, "Accident Ahead." (DlyTrafX30_acc). } \\
\text { ATIS offers alternate route. (DlyTrafX30_alt). } \\
\text { ATIS suggests an alternate route and says, "Gas/Food/Lodging Available." (DlyTrafX30_svc). } \\
\text { ATIS says, "Alternate route guided by State Police." (DlyTrafX30_SP). }\end{array}$ \\
\hline Traffic has continued to move very slowly for over 1 hour. & $\begin{array}{l}\text { The next exit is visible. No additional information is provided. (DlyTrafX60_no). } \\
\text { ATIS offers alternate route. (DlyTrafX60_alt). } \\
\text { ATIS suggests an alternate route and says, "Gas/Food/Lodging Available." (DlyTrafX60_svc). } \\
\text { ATIS says, "Alternate route guided by State Police." (DlyTrafX60_SP). } \\
\text { Public radio suggests and describes an alternate route. (DlyTrafX60_rad). }\end{array}$ \\
\hline $\begin{array}{l}\text { Traffic is still extremely congested and has continued to } \\
\text { move very slowly for over } 2 \text { hours. }\end{array}$ & $\begin{array}{l}\text { ATIS offers alternate route. (DlyTrafX120_alt). } \\
\text { ATIS suggests an alternate route and says, "Gas/Food/Lodging Available." (DlyTrafX120_svc). } \\
\text { ATIS says, "Alternate route guided by State Police." (DlyTrafX120_SP). } \\
\text { Public radio suggests and describes an alternate route. (DlyTrafX120_rad). }\end{array}$ \\
\hline
\end{tabular}

${ }^{a}$ Variable names for each information scenario are provided in parentheses. 
TABLE 4 Percentage of Respondents Who Would Divert After Given Congestion Length When Provided with Specified Information

\begin{tabular}{|c|c|c|c|c|}
\hline \multirow[b]{2}{*}{ Information Scenario $^{a}$} & \multicolumn{4}{|c|}{$\begin{array}{l}\text { Percentage Diverting for } \\
\text { Given Unexpected Congestion } \\
\text { Period (in minutes) }\end{array}$} \\
\hline & 0 & 30 & 60 & 120 \\
\hline DlyTrafXX_alt & 32.5 & 75.1 & 80.1 & 84.2 \\
\hline DlyTrafXX_svc & 32.5 & 78.9 & 87.5 & 92.2 \\
\hline DlyTrafXX_SP & 32.5 & 84.3 & 89.5 & 93.8 \\
\hline DlyTrafXX_rad & 32.5 & - & 82.2 & 88.9 \\
\hline
\end{tabular}

NOTE: - indicates this response was not queried in the survey.

${ }^{a}$ Information scenario titles and descriptions are shown in Table 3.

when provided with ATIS information on alternate routes, alternate routes and services available, the guidance of state police, and alternate route information using public radio. This same information is shown graphically in Figure 1. In the DlyTrafXX_svc scenario, evacuees are provided with information on the availability of gas, food, and lodging on the alternate route.

Detailed analysis of survey results revealed that an evacuee's decision of whether or not to take an alternate route when faced with congestion was associated with two primary factors:

1. Length of time congestion was experienced (or expected) and

2. Whether or not information on the congestion was provided to drivers and its detail.

When asked what they would do if during an evacuation traffic first became congested and slowed to less than $10 \mathrm{mph}, 32.5 \%$ of sample respondents indicated that they would take an alternate route immediately. If congestion continued for first one half hour and then one full hour of delay but no information on alternate routes was provided, the percentage who would alter routes increased by almost half to just over $45 \%$. As one would expect, respondents said they would be more likely to take an alternate route the longer they had been in congested traffic. Responses indicated a higher probability to divert when information was provided that increased drivers' confidence in the route and available services. By comparison, when after 30 min of congestion ATIS suggested an alternate route, fully
$75 \%$ of respondents said they would take it; after $1 \mathrm{~h}$, suggestion of an alternate route resulted in $80 \%$ of respondents expecting to detour. When more than just alternate route information was provided, the likelihood of altering routes increased even more.

Staging state police officers to guide travelers resulted in the highest proportion of drivers choosing to divert, perhaps a reflection of driver confidence in law enforcement personnel. However, the increase in drivers choosing to divert when state police were employed was less than $2.5 \%$ greater than that obtained through use of ATIS, a percentage that may be too small to justify tying up valuable assets.

\section{Diversion and Destination Choices}

The type of intended destination (residence, shelter, motel, or other) was suspected of being an important factor in the detour decision. Approximately $40 \%$ of survey respondents planned to go to a hotel or motel, and researchers hypothesized that these evacuees would be more likely than others to choose to detour if highway message signs indicated that lodging was available. However, although a slightly higher percentage of evacuees traveling to hotels or motels said they would take an alternate route to bypass congestion (73.8\%), the difference was not statistically significant from the percentage of all evacuees who would detour $(72.1 \%)$. Researchers also suspected that the propensity of an evacuee choosing to detour might be related to the total planned distance of the evacuation from origin to destination. When survey results were segmented into those expecting to travel less than $75 \mathrm{mi}$ and those traveling greater than $75 \mathrm{mi}$, less than a $0.1 \%$ difference was identified. Thus, on the basis of statistical evidence, the type of destination and the distance of the total evacuation were discounted as key contributors to the detour decision.

\section{Comparing Diversion During Routine Driving and Evacuation}

Researchers searched for similarities between past behavior and the evacuation decision. Just under $2 / 3$ of survey respondents $(62.4 \%)$ reported having detoured in the previous month to avoid congestion. Of these, $74.4 \%$ anticipated that they would detour in the evacuation scenario. This result differed by less than $2.5 \%$ from all respondents. Survey data also allowed isolating the responses of those who

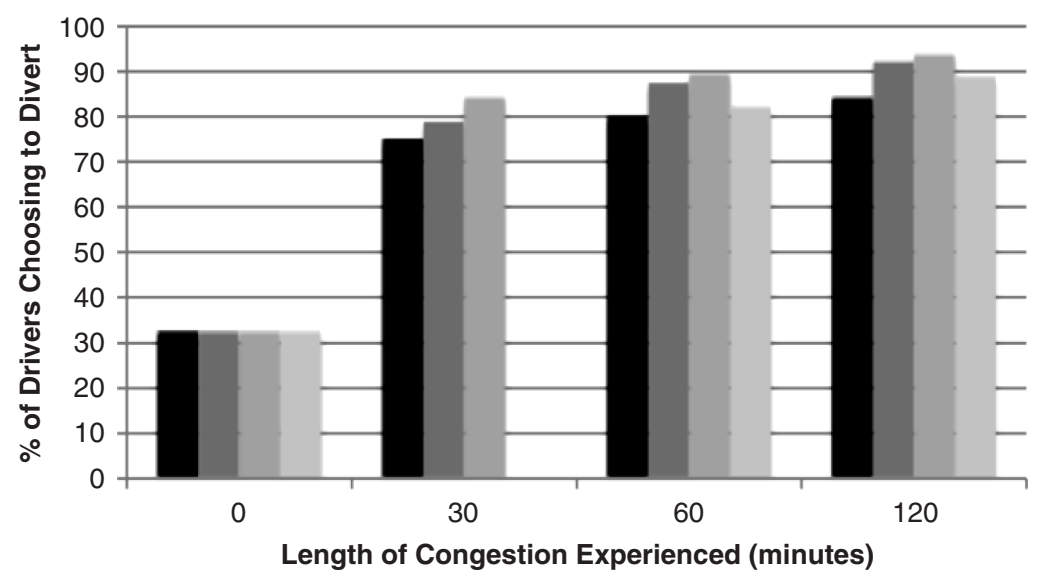

FIGURE 1 Percent of drivers diverting for each scenario at each time increment.

\author{
- DlyTrafXX_alt \\ DlyTrafXX_svc \\ - DlyTrafXX_SP \\ n DlyTrafXX_rad
}


reported that they detoured to avoid congestion at least weekly. This segment composed $35.3 \%$ of the survey analysis group. Of this segment, $72.1 \%$ anticipated detouring in the questioned scenario, a result equal to the percentage of all respondents who expected to detour, regardless of whether or not they frequently altered routes to avoid congestion. Researchers determined that these past driving characteristics could not be used to forecast the decision expected in the congested evacuation scenario.

An additional comparison was completed to examine the correlation between previous route changes made as a result of variable message sign (VMS) prompting and anticipated route changes during an evacuation. Coincidentally, the same proportion of respondents in the analysis group reported having previously detoured as a result of VMS prompting as were expected to detour during a congested evacuation (72.1\% of all respondents). However, one-quarter of the members making up the two decision groups differed. This disparity prevented the VMS influence marker from being used to forecast decisions in the congested evacuation scenario. However, the significant difference in the two groups calls into question what causes the difference in decisions. What leads the same drivers to make contrary decisions in routine and crisis circumstances? Information gathered in the survey was not sufficient to provide that answer; the question is deserving of further investigation.

\section{Information Source}

The survey asked respondents to indicate the traffic information sources they used while driving from a list of five (respondents marked all applicable sources). Listed sources included radio, mobile phones, highway message signs, in-car Global Positioning Systems (GPS), and the Internet. The decisions respondents expected to make were compared with the sources they claimed to use for traffic information. Just over $90 \%$ of respondents reported that they used radio reports to obtain traffic information. Variable message signs were used by approximately $70 \%$ of respondents; one-half used cellular phones and approximately one-third used GPS and the Internet. The extent of respondents who reported using traffic information sources was significantly higher than found in previous studies, such as Mehndiratta et al. (16) and Yim et al. (23). This was true especially in regard to the use of higher-tech sources - cellular phones, GPS, or the Internet. In addition, the assessed influence of information sources was also higher than in the earlier studies. This higher usage may be a result of the more critical situation (an evacuation and not normal commuting), but could also be a reflection of the increased use of technology by individuals in the time since the earlier studies. Interestingly, within each information source segment, the apparent influence of the information on the decision made was fairly constant for each scenario. For example, when respondents were told only alternate route information was provided, $57.2 \%$ indicated they would divert by the 2-h point (time spent in congestion). No information group varied by more than $2.5 \%$ on this decision. Similar results were found for each scenario.

\section{Decision-Making Model}

To allow use of survey results in a decision-making model, curvefitting software was used to identify a representative function for each information scenario. Although 631 individual responses were assessed, only four data points (the four queried time points) were available for each respondent's scenario answers. Bootstrapping techniques were used to improve the accuracy of analysis. This was implemented by constructing eight resample data sets from the 631 responses. Each data set included 100 responses randomly selected with replacement from the original data.

An offset Michaelis-Menten equation was selected to represent the discrete data obtained as a continuous curve. This equation is written as follows:

$$
y(t)=\frac{a * t}{b+t}+c
$$

where

$$
\begin{aligned}
y(t)= & \text { percentage of evacuees expecting to divert at a time } t \text { for } \\
& \text { the given scenario, } \\
t= & \text { time length of congestion in minutes ( } x \text {-axis value), } \\
a= & \text { coefficient determined by analysis, } \\
b= & \text { value of time occurring when } y(t)=1 / 2 *\left[y_{\max }-y(0)\right], \text { and } \\
c= & \text { value of } y \text { at } t=0(y \text {-axis intercept). }
\end{aligned}
$$

Figure 2 shows the results of the DlyTrafXX_alt scenario (ATIS provides information on an alternate route) when plotted by using the calculated coefficient values. Approximately one-third of respondents indicated that they would divert even with no information; this results in a value of 33.92 when $t$ is equal to zero. Note that the $t$-value when the $y$-axis value is $1 / 2$ of the distance from $y$-intercept to its maximum is equal to $b$. Table 5 provides the coefficient values for each scenario as calculated by using the bootstrapping technique. Each scenario reflects the integrated runs of eight data sets of 100 responses

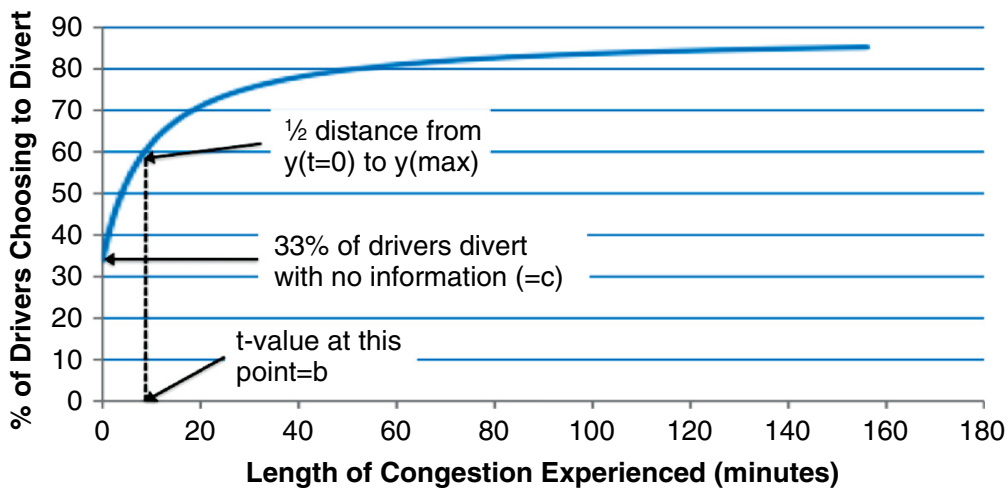

FIGURE 2 DIyTrafXX_alt plot using Michaelis-Menten equation. 
TABLE 5 Michaelis-Menten Coefficient Values for Each Scenario

\begin{tabular}{llrl}
\hline & \multicolumn{3}{l}{$\begin{array}{l}\text { Coefficient Values for } \\
\text { Each Scenario }\end{array}$} \\
\cline { 2 - 4 } Information Scenario $^{a}$ & \multicolumn{1}{c}{$a$} & \multicolumn{1}{c}{$b$} & \multicolumn{1}{c}{$c$} \\
\hline DlyTrafXX_alt & 54.35 & 9.31 & 33.92 \\
DlyTrafXX_svc & 66.42 & 13.57 & 33.92 \\
DlyTrafXX_SP & 61.04 & 6.16 & 33.92 \\
DlyTrafXX_rad & 61.04 & 14.80 & 33.92 \\
\hline
\end{tabular}

${ }^{a}$ Information scenario titles and descriptions are shown in Table 3.

each. These coefficient values were then used to predict values for the four times in each scenario and the standard deviation for each curve calculated.

Table 6 provides the predicted values, the standard deviation values for the percent diverting, and the empirical results using all 631 responses as a single data set. Note the strong agreement between predicted values using the developed equation and the relatively small standard deviation. Demographic categories such as age, gender, education level, household income, and household size were also expected to correlate with the types and sources of information considered to be of great performance or used most frequently. It was hypothesized that these information trends could then be used to more accurately forecast route alteration choices. That was not supported by survey results.

By using the demographic variables, regression analysis of data yielded adjusted $R$-squared $\left(R^{2}\right)$ values of approximately $6 \%$ or less when various route alteration choices were selected as the dependent variables. The $R^{2}$ value provides the proportion of variance in the dependent variable that is attributable to independent variables, indicating that the decisions made by evacuees could not be predicted by using demographic identifiers. As a further step, bivariate correlation testing of all variable pairs was conducted. No demographic relationships common to decision selections could be identified.

TABLE 6 Predicted Values Compared with Complete Sample Data (631 Responses)

\begin{tabular}{lllllll}
\hline & & \multicolumn{5}{c}{$\begin{array}{l}\text { Percentage Diverting for Given } \\
\text { Congestion Period (in minutes) }\end{array}$} \\
\cline { 3 - 7 } $\begin{array}{l}\text { Information } \\
\text { Scenario }\end{array}$ & & 0 & \multicolumn{1}{c}{30} & 60 & 120 & SD \\
\hline DlyTrafXX_alt & Predicted & 33.9 & 75.4 & 81.0 & 84.3 & 3.74 \\
& All data & 32.5 & 75.1 & 80.1 & 84.2 & \\
& Difference & -1.4 & 0.7 & -0.9 & -0.1 & \\
DlyTrafXX_svc & Predicted & 33.9 & 79.6 & 88.1 & 93.6 & 3.28 \\
& All data & 32.5 & 78.9 & 87.5 & 92.2 & \\
& Difference & -1.4 & -0.7 & -0.6 & -1.4 & \\
DlyTrafXX_SP & Predicted & 33.9 & 85.9 & 90.7 & 93.5 & 3.34 \\
& All data & 32.5 & 84.3 & 89.5 & 93.8 & \\
DlyTrafXX_rad & Difference & -1.4 & -1.6 & -1.2 & 0.3 & \\
& Predicted & 33.9 & & 82.9 & 88.3 & 3.05 \\
& All data & 32.5 & & 82.2 & 88.9 & \\
& Difference & -1.4 & & -0.7 & 0.6 & \\
\hline
\end{tabular}

NOTE: $\mathrm{SD}=$ standard deviation.

${ }^{a}$ Information scenario titles and descriptions are shown in Table 3.

\section{VALIDATION}

The Hampton Roads, Virginia, region has not experienced a fullforce hurricane in more than 20 years. The region has never had a mandatory evacuation, and when Hurricane Isabel struck with tropical storm strength in 2003, few residents evacuated the region. Models of evacuee behavior therefore must depend on self-reported data reserved for this purpose. Of the 841 valid survey responses received, $25 \%$ were randomly selected and reserved for validation testing. The model previously described was first tested against the complete reserved data, then four sets of bootstrapped data, each of which included 70 responses randomly selected with replacement each time from the full reserve set.

Predictive equation results were compared with the full set of $25 \%$ of all responses selected at random and reserved for validation from the complete data set, then compared with the average values obtained from the four bootstrap data runs, and finally compared with the averaged results of the four bootstrapped runs and the full reserved data set. Results from this comparison and the standard deviations calculated from the bootstrapped data analysis are provided in Table 7. Predicted values compared very favorably with values calculated from the complete set of reserved data, with all following within $\pm 2.6 \%$, well within the calculated standard deviations. The smaller bootstrapped data sets, as would be expected, were slightly less well defined but still agreed well with predicted values. When results from the bootstrapped data were integrated with results from the complete data set and then compared with the results predicted by the modeling equation, only the values when congestion was first encountered fell outside one standard deviation.

\section{APPLICATION}

A decision-making simulation using these results is being incorporated into a dynamic evacuation simulation. The simulation includes dynamic changes to congestion (as a result of drivers diverting) and dynamic changes to detour opportunity (because not all drivers will be in a position to divert, even though they might choose to do so). It also allows assessment of announcement timing (expediting or delaying ATIS reports) on traffic flow. The simulation, enriched with behavioral analysis, will allow more accurate forecasting of evacuee decisions when evacuees are faced with congestion and the impact on traffic flow, enabling more effective ATIS use. Initial testing of the simulation is complete (24).

\section{LIMITATIONS}

It is important to note the scope and assumptions of analysis:

- The survey was intended to gather sufficient information to provide data for behavior-based testing. Given resource constraints, a representative sample of the region's population could not be obtained. In particular, younger and lower-income citizens were underrepresented. The high number of survey responses provides some mitigation, but before using these results in a real-world situation, a regionally specific, demographically accurate survey must be conducted.

- The survey and subsequent analyses target residents in the Hampton Roads region of Virginia. Results should not be generalized to other areas without further study. 
TABLE 7 Predicted Values Compared with Values from Reserved Data (210 Responses)

\begin{tabular}{|c|c|c|c|c|c|c|}
\hline \multirow[b]{2}{*}{ Information Scenario $^{a}$} & \multirow[b]{2}{*}{ Aspect } & \multicolumn{5}{|c|}{$\begin{array}{l}\text { Percentage Diverting for Given Congestion } \\
\text { Period (min) }\end{array}$} \\
\hline & & 0 & 30 & 60 & 120 & SD \\
\hline \multirow[t]{7}{*}{ DlyTrafXX_alt } & Predicted & 33.9 & 75.4 & 81.0 & 84.3 & 3.74 \\
\hline & All reserved data & 31.3 & 77.5 & 80.4 & 82.7 & 3.74 \\
\hline & Difference & -2.6 & 2.1 & -0.6 & -1.6 & 3.74 \\
\hline & Average four bootstrapped runs & 30.2 & 76.3 & 78.6 & 81.8 & 3.74 \\
\hline & Difference with predicted & 3.7 & -0.9 & 2.4 & 2.5 & 3.74 \\
\hline & Average five $\mathrm{V} \& \mathrm{~V}$ runs & 30.4 & 76.5 & 79.0 & 82.0 & 3.74 \\
\hline & Difference & 3.5 & -1.1 & 2.0 & 2.3 & 3.74 \\
\hline \multirow[t]{7}{*}{ DlyTrafXX_svc } & Predicted & 33.9 & 79.6 & 88.1 & 93.6 & 3.28 \\
\hline & All reserved data & 31.3 & 79.9 & 86.6 & 91.9 & 3.28 \\
\hline & Difference & -2.6 & 0.3 & -1.5 & -1.7 & 3.28 \\
\hline & Average four bootstrapped runs & 30.2 & 81.1 & 84.7 & 92.5 & 3.28 \\
\hline & Difference with predicted & 3.7 & -1.5 & 3.4 & 1.1 & 3.28 \\
\hline & Average five $\mathrm{V} \& \mathrm{~V}$ runs & 30.4 & 80.8 & 85.1 & 92.4 & 3.28 \\
\hline & Difference & 3.5 & -1.2 & 3.0 & 1.2 & 3.28 \\
\hline \multirow[t]{7}{*}{ DlyTrafXX_SP } & Predicted & 33.9 & 85.9 & 90.7 & 93.5 & 3.34 \\
\hline & All reserved data & 31.3 & 88.0 & 90.9 & 94.2 & 3.34 \\
\hline & Difference & -2.6 & 2.1 & 0.2 & 0.7 & 3.34 \\
\hline & Average four bootstrapped runs & 30.2 & 84.0 & 87.2 & 94.3 & 3.34 \\
\hline & Difference with predicted & 1.1 & 4.1 & 3.8 & 1.1 & 3.34 \\
\hline & Average five $\mathrm{V} \& \mathrm{~V}$ runs & 30.4 & 84.8 & 87.9 & 94.3 & 3.34 \\
\hline & Difference & 3.5 & 1.1 & 2.8 & -0.8 & 3.34 \\
\hline \multirow[t]{7}{*}{ DlyTrafXX_rad } & Predicted & 33.9 & & 82.9 & 88.3 & 3.05 \\
\hline & All reserved data & 31.3 & & 82.8 & 89.0 & 3.05 \\
\hline & Difference & -2.6 & & -0.1 & 0.7 & 3.05 \\
\hline & Average four bootstrapped runs & 30.2 & & 82.2 & 89.7 & 3.05 \\
\hline & Difference with predicted & 1.1 & & 0.6 & -0.7 & 3.05 \\
\hline & Average five $V \& V$ runs & 30.4 & & 82.3 & 89.5 & 3.05 \\
\hline & Difference & 3.5 & & 0.6 & -1.2 & 3.05 \\
\hline
\end{tabular}

NOTE: $\mathrm{V} \& \mathrm{~V}=$ verification and validation.

${ }^{a}$ Information scenario titles and descriptions are shown in Table 3.

- Analyses were completed assuming that particular information scenarios continued throughout the examined period. For example, in the DlyTrafXX_alt stream, curves were developed by assuming that information on alternative routes was provided throughout the evacuation period. If the type of information provided changes during an evacuation (for example, signs shift from providing only alternate course information to also providing information on services), users can apply the new decision percentages only to the number of drivers still "in play."

- In any survey questioning the future intentions of respondents, one must keep in mind that intentions may differ from the actions that are actually taken during an event.

\section{CONCLUSIONS}

This study shows that the decisions made by hurricane evacuees on whether or not to detour when faced with congestion are predictable and, through the discerning use of ATIS, somewhat controllable by transportation managers. Survey responses were obtained from adult drivers in the Hampton Roads region of Virginia. Results from analysis of stated preferences indicate that during a hurricane evacuation, drivers will be most motivated to use an alternate route when there is an extended period of congestion (longer expected delays on intended route) and when ATIS provides detailed information on alternate routes. Analyses indicate no statistical evidence for asso- ciations between demographics (e.g., age or gender) and drivers' motivation to detour, for this sample. Although altering the information provided via ATIS may influence the decisions made by only a small percentage of drivers, that may significantly affect the transportation system. Route changes of just $5 \%$ of 500,000 drivers means that 25,000 vehicles may alter paths.

Researchers in the field may find this study useful. Evacuation simulations increasingly use dynamic influences (dynamic traffic assignment, incorporation of accident and incident impacts, etc.); modeling evacuees' intentions when they are faced with changes to the travel environment is another step in this direction. A more complete simulation of evacuations, including expanding modeling of driver behavior and considering additional evacuation causes, will provide a better understanding of transportation system performance and enable better planning. Similar studies in other regions anticipating major evacuations will be useful.

The findings are likely to be of interest to emergency managers and ATIS providers seeking to anticipate transportation problems and develop solutions. This study highlights that if proper incident management procedures and intelligent transportation systems are in place before hurricane evacuations, better management of the evacuation is possible. There is a need for better planning to continue communicating with travelers and to be able to respond to incidents.

Supporters of ATIS enhancements may find this study beneficial in efforts to convince others of the exceptional influence of ATIS, not only in daily situations but also during crisis response. 


\section{REFERENCES}

1. Baker, E. J. Hurricane Evacuation Behavior. International Journal of Mass Emergencies and Disasters, Vol. 9, No. 2, 1991, pp. 287-310.

2. Prater, C. S., D. Wenger, and K. Grady. Hurricane Bret Post Storm Assessment: A Review of the Utilization of Hurricane Evacuation Studies and Information Dissemination. Texas A\&M University Hazard Reduction and Recovery Center. College Station, Tex., 2000. http://archone.tamu.edu/ hrrc/Publications/researchreports/index.html. Accessed June 16, 2009.

3. Lindell, M. K., J.-C. Lu, and C. S. Prater. Household Decision-Making and Evacuation in Response to Hurricane Lili. Natural Hazards Review, Nov. 2005, pp. 171-179.

4. Southworth, F. Regional Evacuation Modeling: A State of the Art Review. Prepared for the U.S. Department of the Army, Office of the Assistant Secretary, Installations, Logistics and Environment, Washington, D.C., under Interagency Agreement DOE 1769-1354-A1, March 1991.

5. Southworth, F., and S.-M. Chin. Network Evacuation Modeling for Flooding as a Result of Dam Failure. Environment and Planning A, Vol. 19, 1987, pp. 1543-1558.

6. Hobeika, A. G., and C. Kim. Comparison of Traffic Assignments in Evacuation Modeling. IEEE Transactions on Engineering Management, Vol. 45, No. 2, May 1998, pp. 192-198.

7. Fu, H., C. G. Wilmot, H. Zhang, and E. J. Baker. Modeling the Hurricane Evacuation Response Curve. In Transportation Research Record: Journal of the Transportation Research Board, No. 2022, Transportation Research Board of the National Academies, Washington, D.C., 2007, pp. 94-102.

8. Wilmot, C. G., and B. Mei. Comparison of Alternative Trip Generation Models for Hurricane Evacuation. Natural Hazards Review, 2004, pp. 170-178.

9. Barrett, B., B. Ran, and R. Pillai. Developing a Dynamic Traffic Management Modeling Framework for Hurricane Evacuation. In Transportation Research Record: Journal of the Transportation Research Board, No. 1733, TRB, National Research Council, Washington, D.C., 2000, pp. 115-121.

10. Murray-Tuite, P. M., and H. S. Mahmassani. Transportation Network Evacuation Planning with Household Activity Interactions. In Transportation Research Record: Journal of the Transportation Research Board, No. 1894, Transportation Research Board of the National Academies, Washington, D.C., 2004, pp. 150-159.

11. Wolshon, B., E. U. Hamilton, C. Wilmot, and M. Levitan. Review of Policies and Procedures for Hurricane Evacuation. I: Transportation Planning, Preparedness, and Response. Natural Hazards Review, Vol. 6, No. 3, 2005, pp. 129-142.

12. Wolshon, B., E. U. Hamilton, M. Levitan, and C. Wilmot. Review of Policies and Practices for Hurricane Evacuation. II: Traffic Operations, Management, and Control. Natural Hazards Review, Vol. 6, No. 3, 2005, pp. 143-161.

13. Robinson, R. M., A. J. Khattak, J. A. Sokolowski, P. Foytik, and X. Wang. Role of Traffic Incidents in Hampton Roads Hurricane Evacuations.
Presented at 88th Annual Meeting of the Transportation Research Board, Washington, D.C., 2009.

14. Liu, Y., X. Lai, and G.-L. Chang. Cell-Based Network Optimization Model for Staged Evacuation Planning Under Emergencies. In Transportation Research Record: Journal of the Transportation Research Board, No. 1964, Transportation Research Board of the National Academies, Washington, D.C., 2006, pp. 127-135.

15. Dixit, V. V., and E. Radwan. Strategies to Improve Dissipation into Destination Networks Using Macroscopic Network Flow Models. Presented at 87th Annual Meeting of the Transportation Research Board, Washington, D.C., 2008.

16. Mehndiratta S. R., M. A. Kemp, J. E. Lappin, and E. Nierenberg. Likely Users of Advanced Traveler Information Systems: Evidence from the Seattle Region. In Transportation Research Record: Journal of the Transportation Research Board, No. 1739, TRB, National Research Council, Washington, D.C., 2000, pp. 15-24.

17. Goulias, K. G., T.-G. Kim, and O. Pribyl. A Longitudinal Analysis of Awareness and Use for Advanced Traveler Information Systems. Journal of Intelligent Transportation Systems, Vol. 8, No. 1, 2004, pp. 3-17.

18. Khattak A., A. Polydoropoulou, and M. Ben-Akiva. Modeling Revealed and Stated Pretrip Travel Response to Advanced Traveler Information Systems. In Transportation Research Record 1537, TRB, National Research Council, Washington, D.C., 1996, pp. 46-54.

19. Khattak A. J., X. Pan, B. M. Williams, N. M. Rouphail, and Y. Fan. Traveler Information Delivery Mechanisms: Impacts on Consumer Behavior. In Transportation Research Record: Journal of the Transportation Research Board, No. 2069, Transportation Research Board of the National Academies, Washington, D.C., 2008, pp. 77-84.

20. Tsirimpa, A., A. Polydoropoulou, and C. Antoniou. Development of a Mixed Multi-Nomial Logit Model to Capture the Impact of Information Systems on Travelers' Switching Behavior. Journal of Intelligent Transportation Systems: Technology, Planning, and Operations, Vol. 11, No. 2, 2007, pp. 79-89.

21. Virginian-Pilot summary of The Scarborough Report 2006, Rel. 2. http://thevirginianpilot.com/advertising/demoLife.html. Accessed July 24, 2009.

22. Robinson, R. M. Hampton Roads Hurricane Transportation Study. Report Number V07-008. Provided to the Virginia Department of Emergency Management, Richmond, Va., June 2008.

23. Yim, Y., A. J. Khattak, and J. Raw. Traveler Response to New Dynamic Information Sources: Analyzing Corridor and Areawide Behavioral Surveys. In Transportation Research Record: Journal of the Transportation Research Board, No. 1803, Transportation Research Board of the National Academies, Washington, D.C., 2002, pp. 66-75.

24. Robinson, R. M., A. Khattak, and P. Foytik. Forecasting Driver DecisionMaking During Catastrophic Event Evacuations. Presented at National Evacuation Conference, New Orleans, La., Feb. 4, 2010.

The Transportation Safety Management Committee peer-reviewed this paper. 